\title{
Potential large missions enabled by NASA's Space Launch System
}

\author{
H. Philip Stahl \\ Randall C. Hopkins, ${ }^{\mathrm{a}}$ Andrew Schnell, ${ }^{\mathrm{a}}$ \\ David Alan Smith, ${ }^{a}$ Angela Jackman, ${ }^{a}$ \\ Keith R. Warfield ${ }^{b}$
}

${ }^{a}$ NASA Marshall Space Flight Center, Huntsville, AL

${ }^{\mathrm{b} C a l i f o r n i a}$ Institute of Technology/Jet Propulsion Laboratory, Pasadena, CA

The payload capacities of NASA's planned Space Launch System (SLS) is a disruptive capability than enables entirely new mission architectures.

- We will review these capacities.

- We will present a flow down from SLS capacities to first order telescope design parameters.

- We will present three specific point designs for potential missions which use the SLS's capacities:
- ATLAST-8
- ATLAST-12
○ HabEx-4 


\section{Introduction}

\section{NA9A Astrophysicists want Larger Observatories}

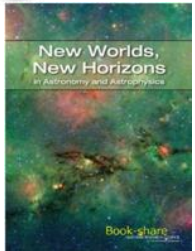

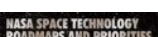

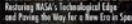
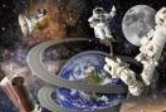

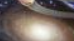

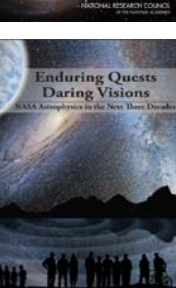

\section{New Worlds, New Horizons Decadal Report:}

New Worlds Technology Development (NWTD) Program to "lay the technical and scientific foundations for a future space imaging and spectroscopy mission".

2012 NASA Space Technology Roadmaps \& Priorities:

New Astronomical Telescopes that enable discovery of habitable planets, facilitate advances in solar physics, and enable the study of faint structures around bright objects ...

2014 Enduring Quests Daring Visions:

8 to $16-\mathrm{m}$ LUVOIR with sensitivity and angular resolution to "dramatically enhance detection of Earth-sized planets to statistically significant numbers, and allow in-depth spectroscopic characterization"; and, "decode the galaxy assembly histories through detailed archeology of their present structure." 
The AURA "Cosmic Birth to Living Earth" Report calls for:

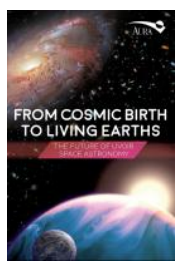

A 12 meter class space telescope with sufficient stability and the appropriate instrumentation can find and characterize dozens of Earth-like planets and make transformational advances in astrophysics.

In response, NASA's "Planning for the 2020 Decadal Survey":

- Habitable Exoplanet Imaging (HabEx)

- LUVOIR Surveyor

as well as Far-IR and an X-Ray Surveyor missions. 


\title{
"AMATEURS THINK ABOUT TACTICS, PROFESSIONALS THINK ABOUT LOGISTICS”
}

\author{
GENERAL ROBERT H. BARROW, USMC \\ (COMMANDANT OF THE MARINE CORPS)
}

Logistics for Space Telescopes are:

- Launch Vehicle Payload Mass Capacity

- Launch Vehicle Payload Volume Capacity

- Budget Amount and Phasing

\section{Launch Vehicle Constraint}

All Missions are constrained by their Launch Vehicle.

- HST and Chandra were designed for Shuttle

\begin{tabular}{|l|l|l|}
\hline & \multicolumn{1}{|c|}{ Payload Mass } & Payload Volume \\
\hline Space Shuttle Capacities & $\begin{array}{l}25,061 \mathrm{~kg}(\mathrm{max} \text { at } 185 \mathrm{~km}) \\
16,000 \mathrm{~kg}(\mathrm{max} \text { at } 590 \mathrm{~km})\end{array}$ & $4.6 \mathrm{~m} \times 18.3 \mathrm{~m}$ \\
\hline Hubble Space Telescope & $11,110 \mathrm{~kg}($ at $590 \mathrm{~km})$ & $4.3 \mathrm{~m} \times 13.2 \mathrm{~m}$ \\
\hline $\begin{array}{l}\text { Chandra X-Ray Telescope } \\
\text { (and Inertial Upper Stage) }\end{array}$ & $22,800 \mathrm{~kg}($ at $185 \mathrm{~km})$ & $4.3 \mathrm{~m} \times 17.4 \mathrm{~m}$ \\
\hline
\end{tabular}

- JWST was designed for Ariane 5

\begin{tabular}{|l|c|l|}
\hline & Payload Mass & Payload Volume \\
\hline Ariane 5 Capacities & $6600 \mathrm{~kg}$ (at SE L2) & $4.5 \mathrm{~m} \mathrm{x} \mathrm{15.5} \mathrm{m}$ \\
\hline James Webb Space Telescope & $6530 \mathrm{~kg}$ (at SE L2) & $4.47 \mathrm{~m} \mathrm{x} 10.66 \mathrm{~m}$ \\
\hline
\end{tabular}




\section{SLS Block Development Schedule}

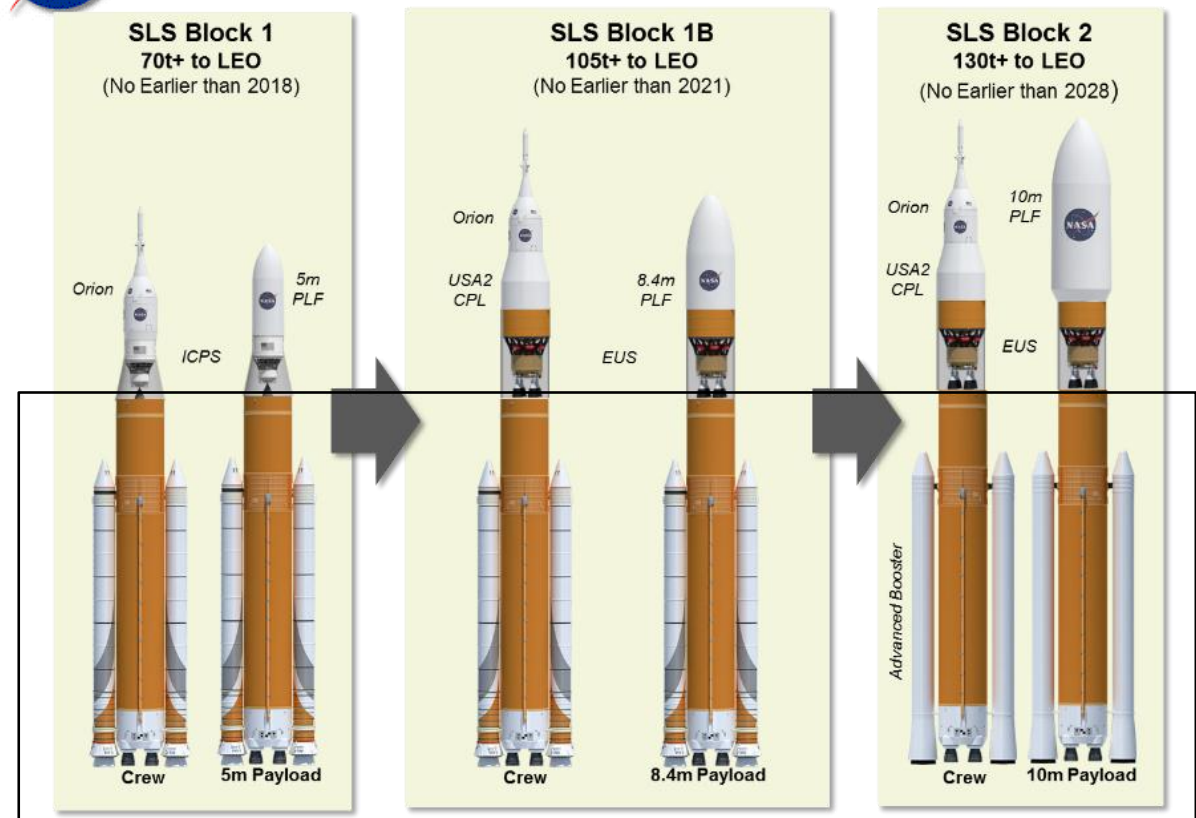

\section{NASA}

SLS Fairing Capacity

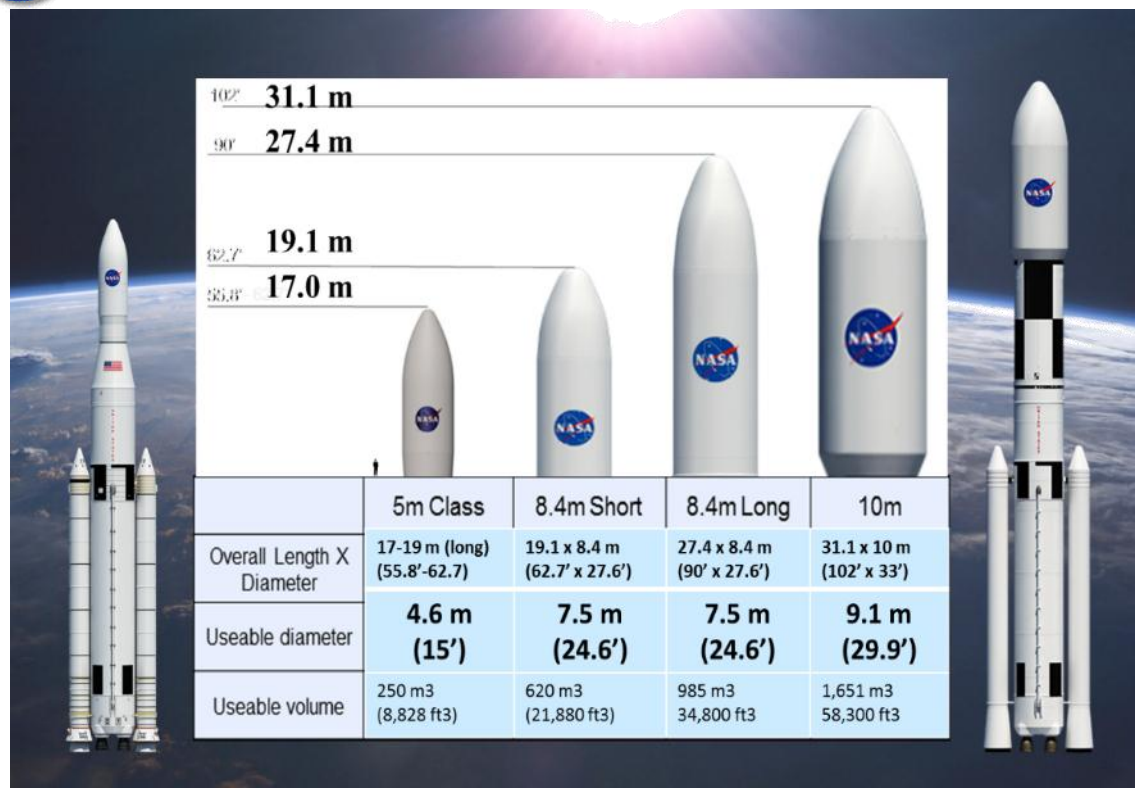




\section{SLS Mass Capacity to Destination (C3)}

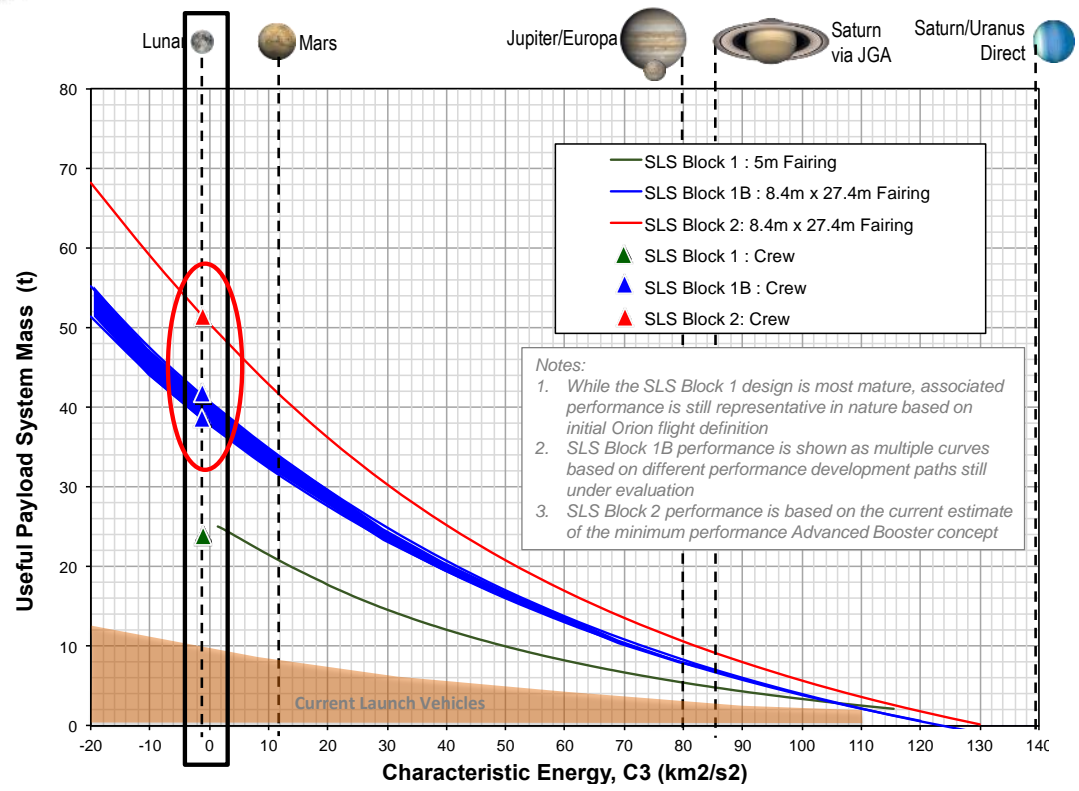

NASA

Design for Affordability 


\section{Mass Drives Cost}

-Some (or many) believe that Mass Drives Cost.

-But they are mistaken.

-They respond by saying that cost models are all based on cost.

-But they are mistaken.

Based on 30 unmanned, earth orbiting missions:

- Spacecraft Cost Mass to the 0.7 power

- Spacecraft Cost $\sim$ Design Maturity to the 1.5 power

Example: JWST is $\sim 1 / 2$ the mass of HST ( $\sim 500 \mathrm{~kg}$ vs $11,110 \mathrm{~kg})$; but, over $2 \mathrm{x}$ the cost of HST ( $\sim 6.5 \mathrm{~B}$ Phase A-D vs $\$ 3 \mathrm{~B})$.

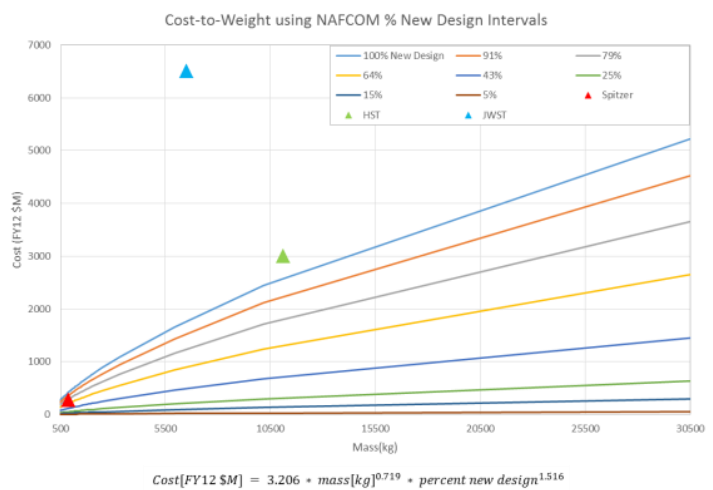




\section{Mass Margin Reduces Risk \& Cost}

According to the US Air Force:

- Biggest drivers for reducing cost are reuse of heritage components and having a high mass margin.

Fox, Bernard, Kevin Brancato, Brien Alkire, "Guidelines and Metrics for Assessing Space System Cost Estimates", RAND Corporation, 2008.

- Additional evidence of cost saving with high mass margin is:

- Free-flying telescopes have lowest design margins and highest cost per unit mass.

- Shuttle attached and SOFIA have different margin rules and lower costs.

- Ground telescopes have the most robust design margins and lowest cost.

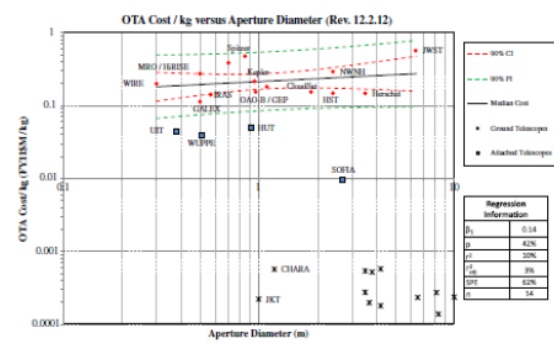

Stahl, H. Philip, "Survey of cost models for space telescopes", Optical Engineering, 49(5) 053004 (May 2010).

-Complexity is required to package a large mission into a small launch vehicle with its mass and volume constraints.

-The mass and volume capacities offered by the SLS enable simpler designs with higher design allowable mass margins.

-Higher mass margins allows use of standard engineering design practices and reduces ground handling risk. 


\section{JWST}

The JWST Independent Comprehensive Review Panel found that JWST is "one of the most complex science missions carried out to date and therefore falls at the high end of the range, greater than $90 \%$, on the complexity index."

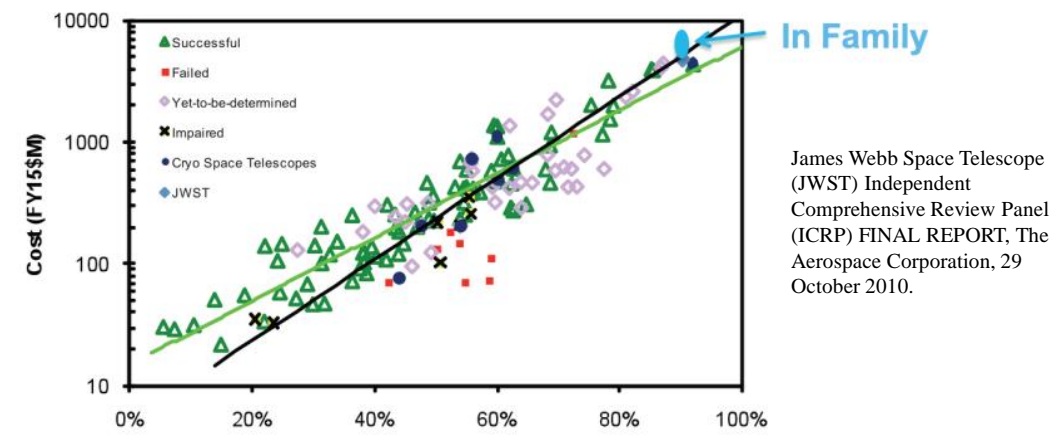




\section{SLS Mass Capacity to Destination (C3)}

\begin{tabular}{|l|c|c|c|c|}
\hline \multicolumn{5}{|c|}{ Available Maximum Payload Mass after Margin for Select SLS Vehicles } \\
\hline SLS & Block-1B min & Block-1B max & Block-2 (10m) & Block-2 (8.4m) \\
\hline Projected Mass to SE-L2 & $35,000 \mathrm{~kg}$ & $40,000 \mathrm{~kg}$ & $45,000 \mathrm{~kg}$ & $50,000 \mathrm{~kg}$ \\
\hline Max Payload with 30\% Margin & $26,900 \mathrm{~kg}$ & $30,800 \mathrm{~kg}$ & $34,600 \mathrm{~kg}$ & $38,500 \mathrm{~kg}$ \\
\hline Max Payload with 43\% Margin & $24,500 \mathrm{~kg}$ & $28,000 \mathrm{~kg}$ & $31,500 \mathrm{~kg}$ & $35,000 \mathrm{~kg}$ \\
\hline
\end{tabular}

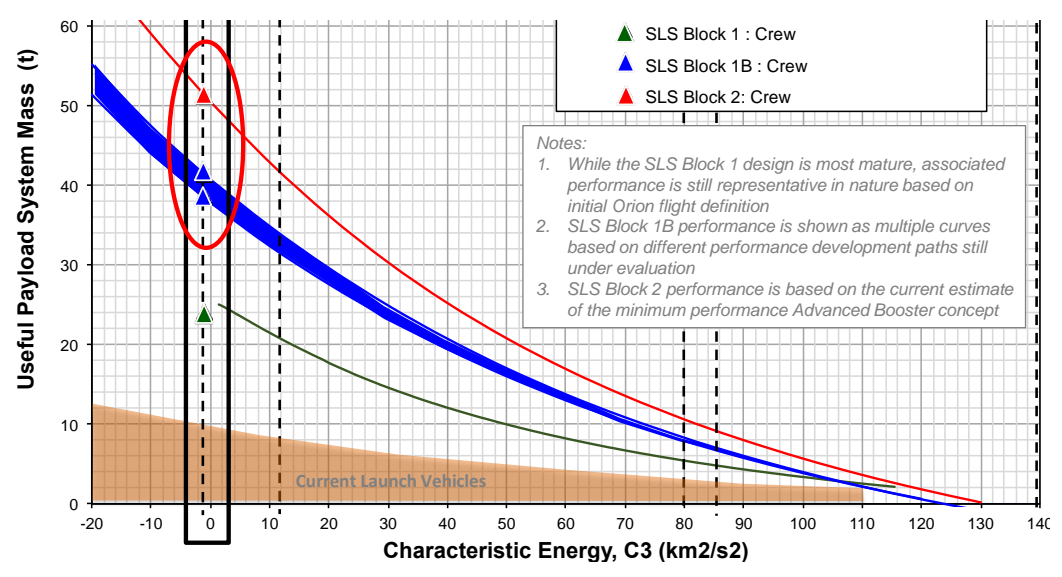

\section{Mass Flow Down}

Mission architecture is driven by mass and volume.

While below is arbitrary, sub-system allocations are reasonable.

\begin{tabular}{|c|c|c|c|}
\hline SLS & Block-1B & Block-2 min & Block-2 max \\
\hline Max Payload Mass with 43\% Margin & $24,500 \mathrm{~kg}$ & $31,500 \mathrm{~kg}$ & $38,500 \mathrm{~kg}$ \\
\hline Spacecraft Allocation (20\% of Payload) & $5,000 \mathrm{~kg}$ & $6,250 \mathrm{~kg}$ & $7,500 \mathrm{~kg}$ \\
\hline Observatory Allocation ( $80 \%$ of Payload) & $20,000 \mathrm{~kg}$ & $25,000 \mathrm{~kg}$ & $30,000 \mathrm{~kg}$ \\
\hline Science Instruments ( $10 \%$ of Observatory) & $2,000 \mathrm{~kg}$ & $2,500 \mathrm{~kg}$ & $3,000 \mathrm{~kg}$ \\
\hline Telescope (PMA, SMA, and Structure) $(90 \%)$ & $18,000 \mathrm{~kg}$ & $22,500 \mathrm{~kg}$ & $27,000 \mathrm{~kg}$ \\
\hline SMA and Structure & $8,000 \mathrm{~kg}$ & $10,000 \mathrm{~kg}$ & $12,000 \mathrm{~kg}$ \\
\hline Primary Mirror Assembly Allocation & $10,000 \mathrm{~kg}$ & $12,500 \mathrm{~kg}$ & $15,000 \mathrm{~kg}$ \\
\hline Primary Mirror Assembly Areal Mass & {$\left[\mathrm{kg} / \mathrm{m}^{2}\right]$} & {$\left[\mathrm{kg} / \mathrm{m}^{2}\right]$} & {$\left[\mathrm{kg} / \mathrm{m}^{2}\right]$} \\
\hline 4 meter diameter $\left(12.5 \mathrm{~m}^{2}\right)$ & 800 & 1000 & 1200 \\
\hline 8 meter diameter $\left(50 \mathrm{~m}^{2}\right)$ & 200 & 250 & 300 \\
\hline 12 meter diameter $\left(100 \mathrm{~m}^{2}\right)$ & 100 & 125 & 150 \\
\hline 16 meter diameter $\left(200 \mathrm{~m}^{2}\right)$ & 50 & 62.5 & 75 \\
\hline
\end{tabular}

Areal Mass for PMA is consistent with state of art.

- $2.4 \mathrm{~m} \mathrm{HST}$ is $1860 \mathrm{~kg}$ for a $460 \mathrm{~kg} / \mathrm{m}^{2}$ areal mass

- $6.5 \mathrm{~m}$ JWST is $\sim 1750 \mathrm{~kg}$ for a $\sim 70 \mathrm{~kg} / \mathrm{m}^{2}$ areal mass

○ $30 \mathrm{~m}$ TMT projected areal mass is $150 \mathrm{~kg} / \mathrm{m}^{2}$ 


\section{Point Designs}

\section{Point Designs}

The MSFC Advanced Concept Office has produced mission concepts for three specific SLS based point designs:

ATLAST-8 $8 \mathrm{~m}$ on-axis monolithic aperture telescope for potential LUVOIR Surveyor mission

ATLAST-12 12m on-axis segmented aperture telescope for potential LUVOIR Surveyor mission

HabEx-4 4 m off-axis telescope for potential Habitable Exoplanet mission
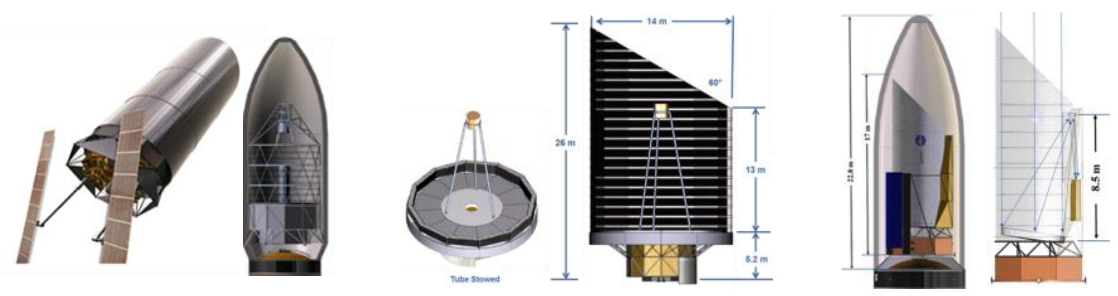
All three use a dual foci Cassegrain/TMD optical design.

- Cassigren foci is Narrow Field, for Coronagraph \& UV IFU

- TMA foci is Wide Field, for Imager \& Multi-Object Spectrograph
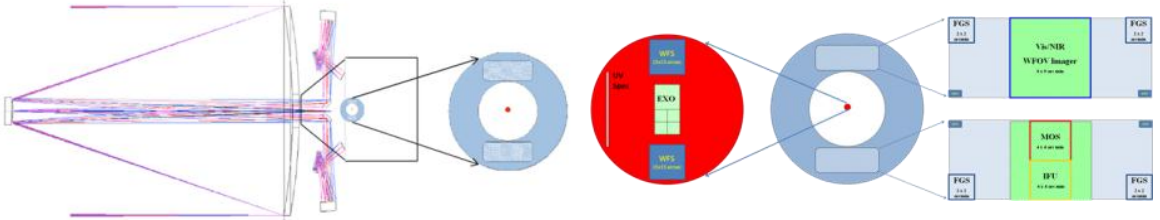

Momentum Management for at least 3000 second Exposures

- ATLAST-8 \& -12 balance Solar Pressure with articulated Solar Panels

- To avoid vibrations, HabEx uses oversized redundant reaction wheels
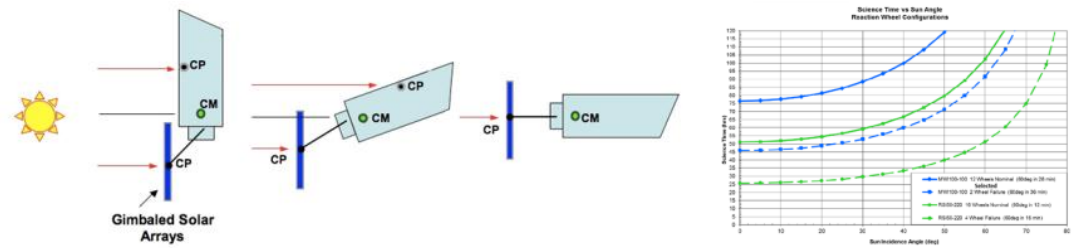

\section{Payload Accommodation}

SLS Fairing Volume enables architectures with minimal deployments.

- HabEx-4 is sized for SLS Block-1B 8.4-m x 27.4-m fairing

- ATLAST-8 \& -12 are sized for SLS Block-2 10-m x 31.1-m fairing.

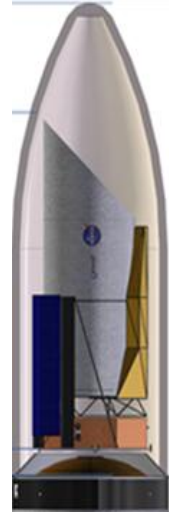

HabEx-4

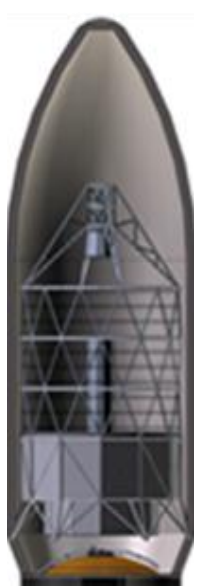

ATLAST-8

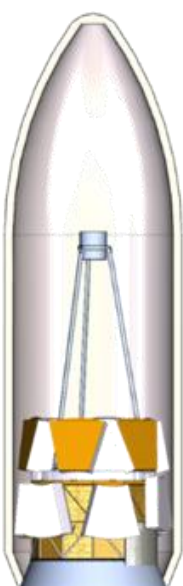

ATLAST-12 


\section{Mass Budget}

SLS Mass Capacity enables high mass margin Architectures:

- HabEx-4 is sized for SLS-1B and requires $~ 50 \%$ of available mass

- ATLAST-8 \& -12 are sized for max mass of SLS-2 with 10-m fairing.

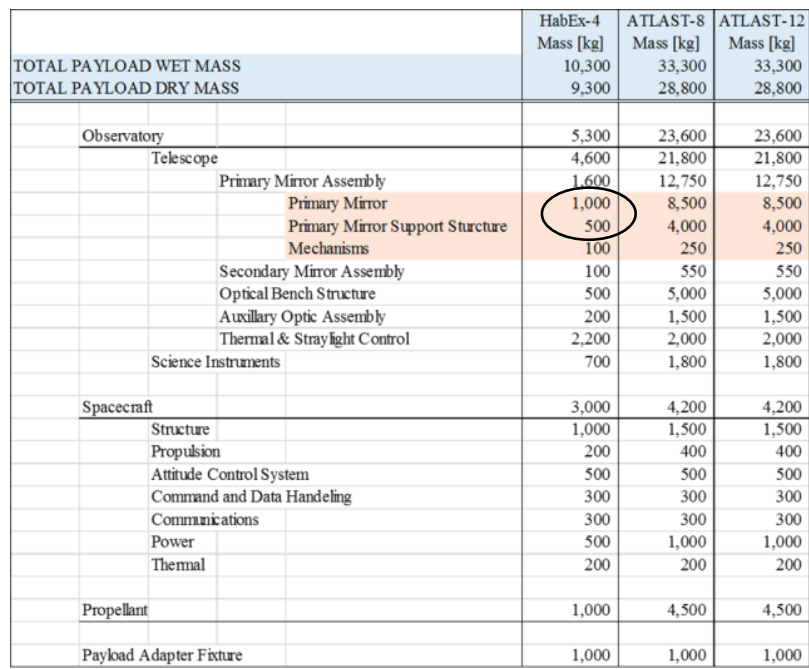

Recent desire is PM with higher stiffness, thus current design is $\sim 2500 \mathrm{~kg}$ for PM and $\sim 1250 \mathrm{~kg}$ for Support.

Well within available mass margin.

Stiff Structures are critical to a space telescope's ability to:

- Survive Launch

- Achieve and Maintain a Stable Wavefront

SLS Mass \& Volume Capacities enable Stiff Structures:

- Stiffness is achieved via structural 'depth' (i.e. volume) and 'mass'.

- ATLAST-8 PM Structure provides a 10X margin of safety to mirror during launch by distributing forces between 66 axial and lateral support points.

- ATLAST-12 PM Structure is 4-meters deep to achieve a $20 \mathrm{~Hz}$ first mode. It survives $5 \mathrm{~g}$ axial and $2 \mathrm{~g}$ lateral loads with 1.4 ultimate safety factor.

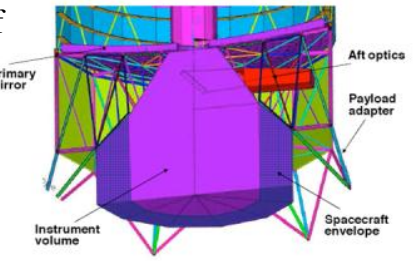
$4 \mathrm{mt}$ mass is driven by $20 \mathrm{~Hz}$ not by launch.
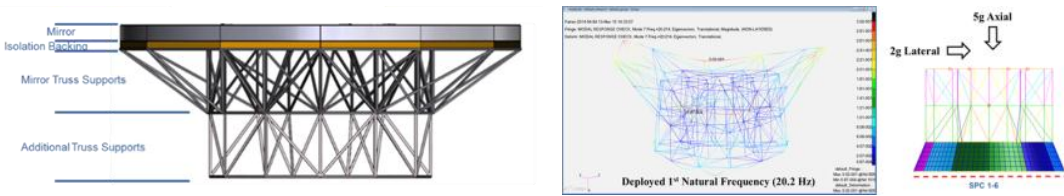


\section{Conclusions}

- The payload capacities of NASA's planned Space Launch System (SLS) is a disruptive capability.

○ 8.4 and 10.0 meter fairings

○ 45 to $55 \mathrm{mt}$ to SE-L2

- SLS's mass and volume capacities enable new classes of mission architectures that use payload design simplicity to reduce cost.

- Presented three point designs for potential missions:

- ATLAST-8

- ATLAST-12

- HabEx-4

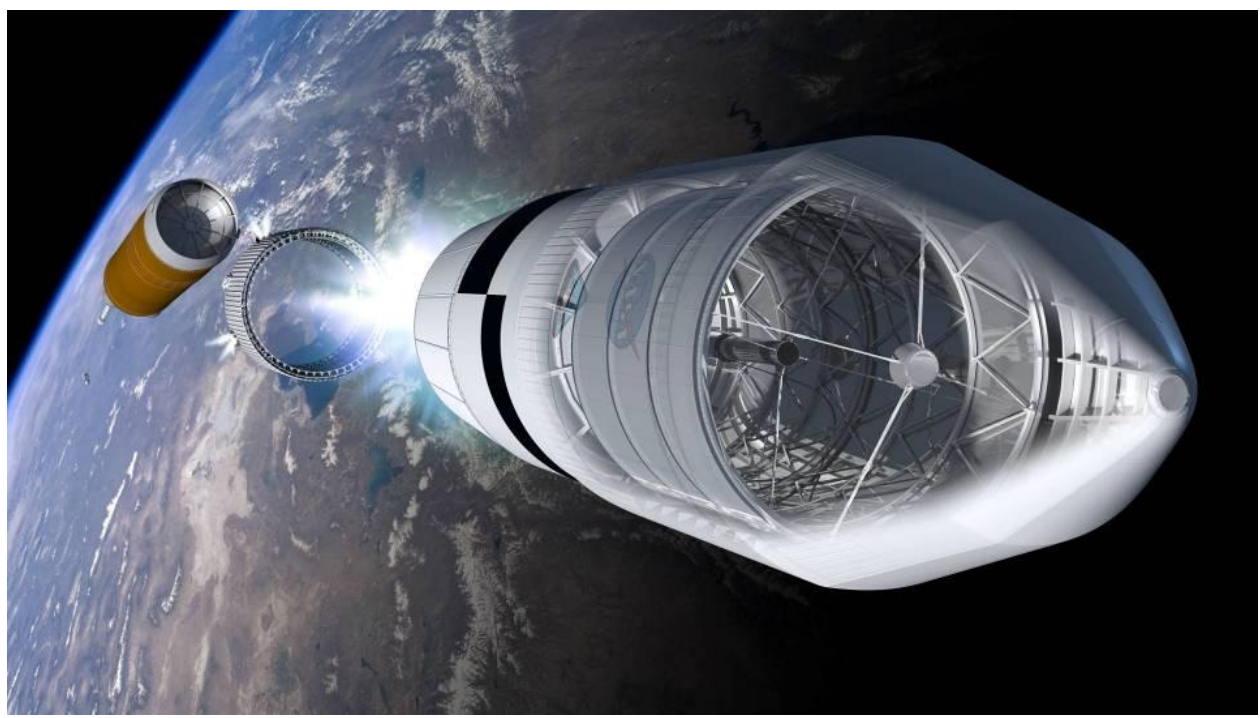

